Review Article

\title{
A Review: Autodissemination of Pyriproxyfen as Novel Strategy to Control Dengue Outbreaks
}

\author{
Ahmad Mohiddin Mohd Ngesom ${ }^{1}$, David Greenhalgh' ${ }^{2}$, Asmalia Md Lasim³, \\ Mazrura Sahani ${ }^{1}$, Rozita Hod ${ }^{4}$ and Hidayatulfathi Othman ${ }^{1 *}$ \\ ${ }^{1}$ Faculty of Health Sciences, Universiti Kebangsaan Malaysia, Jalan Raja Muda Abdul Aziz, \\ 50300 UKM, Kuala Lumpur, Malaysia \\ ${ }^{2}$ Department of Mathematics and Statistics, University of Strathclyde, 26, Rivhmond Street, Glasgow, \\ G11XH, UK \\ ${ }^{3}$ Faculty of Science and Technology, Universiti Kebangsaan Malaysia, Bangi, 43600 UKM, Selangor, Malaysia \\ ${ }^{4}$ Department of Community Health, Faculty of Medicine, Universiti Kebangsaan Malaysia, \\ 56000 UKM, Cheras, Kuala Lumpur, Malaysia
}

\begin{abstract}
The new emergence and re-emergence of arbovirus infections transmitted by Aedes mosquitoes have been spreading across Southeast Asia, Central Africa, United States, tropical Oceania and has become a major of public health concern. These arbovirus diseases were found to have a similar vector, symptoms, and environments. The situation is complex due to no specific vaccine or treatments being available for the diseases. Therefore, vector control is currently the best defense against arbovirus diseases, but with its own challenges such as the difficulty in controlling scattered

ARTICLE INFO

\section{Article history:}

Received: 31 March 2020

Accepted: 27 July 2020

Published: 21 October 2020

DOI: https://doi.org/10.47836/pjst.28.4.01

E-mail addresses:

aksmohiddin@yahoo.com (Ahmad Mohiddin Mohd Ngesom)

david.greenhalgh@strath.ac.uk (David Greenhalgh)

asmaliaccb@gmail.com (Asmalia Md Lasim)

mazrura@ukm.edu.my (Mazrura Sahani)

rozita.hod@ppukm.ukm.edu.my (Rozita Hod)

hida@ukm.edu.my (Hidayatulfathi Othman)

*Corresponding author

breeding sites and biological behavior.

Herein, we present a literature review of studies on current techniques proposed to combat dengue transmission that can fill a crucial gap in vector control programs, which is the inability of conventional control methods to eliminate and destroy cryptic breeding sites. In particular, we focused on the concept of autodissemination, which is a self-delivery technique by manipulating the behavior of mosquitoes, carrying the
\end{abstract}


insecticide and disseminating it to cryptic breeding sites. This technique has shown promising results in some countries and can be considered as an additional tool in a vector control program. Therefore, we conducted Boolean searches in several electronic databases including Google Scholar, PubMed, SciELO and ScienceDirect to identify relevant published data regarding dengue and autodissemination techniques.

Keywords: Aedes, autodissemination, dengue, pyriproxyfen, vector control

\section{INTRODUCTION}

To date, there are more than 300 known species of mosquitoes in the world but with only a small number of species responsible for vector-borne diseases (Caraballo \& King, 2014). Aedes aegypti and Aedes albopictus are the most important vectors for the transmission of dengue, Zika, and chikungunya virus. According to the World Health Organization (WHO), mosquito infections affected more than one third of the world's population and caused about one million deaths annually (WHO, 2016).

Aedes aegypti is the most important disease vector worldwide. It is the principal vector of dengue, chikungunya, yellow fever and Zika viruses. Ae. aegypti is extremely anthropophilic, has frequent blood-feeding behavior, a long lifespan and is closely associated with humans, because of their ability to breed in human dwellings, and preferring to feed on humans even in the presence of other mammals (Faraji et al., 2014). The blood-feeding behavior becomes the primary concern because it is the major component of the dengue virus transmission where an infected patient gets bitten by a mosquito which then carries the virus to another person. Most mosquito species have their preferred distributions, with the Ae. aegypti being the primary vector of the dengue virus, but it is also an efficient vector for other viruses that cause human diseases such as the Zika virus and chikungunya virus.

Meanwhile, Aedes albopictus was found to be able to transmit over more than 20 arboviruses, increasing the risk of humans to mosquito-borne diseases (Wong et al., 2013) and was considered as a secondary vector in importance according to their zoophilic preferences (Delatte et al., 2010). In certain areas around the world, it has become one of the most invasive mosquito species. Ae. albopictus is considered a greater threat compared to Ae. aegypti due to the former's higher survival rate in larval densities (Camara et al., 2016), adaptation to extreme temperatures (Brady et al., 2013) and showing greater survivorship in food-limited competitions (Banerjee et al., 2017; Hopperstad \& Reiskind, 2016).

\section{SEARCH STRATEGY}

We searched PubMed, ScienceDirect, SciELO and Google Scholar with the following keywords: dengue fever; dengue control; vector control; autodissemination; pyriproxyfen; pyriproxyfen autodissemination; horizontal transfer; autodissemination AND dengue or 
malaria; emergence inhibition; and pyriproxyfen (PPF) in several combinations using Boolean searches. Non-English language articles were also included if there was an available English translation. Due to the limited data published in scientific journals, we also explored the databases of leading organization, such as World Health Organization (WHO) and Ministry of Health Malaysia $(\mathrm{MOH})$ and Centers for Disease Control and Prevention (CDC).

\section{Dengue}

Although dengue fever is among the most common mosquito-borne infections in the world, yet it has long been categorized as a "neglected tropical disease" (Faraji et al., 2014). The Chinese medical encyclopedia from the Jin Dynasty (265-420 AD) was probably the first record of which diseases were associated with flying insects. The first recognized dengue epidemics occurred almost simultaneously in Asia, Africa, and North America in the 1780s. The first confirmed case report of dengue hemorrhagic fever in Southeast Asia occurred in Manila in 1953 and during the second outbreaks in 1956. Today, dengue fever has become one of the major public health issues and is endemic in more than 125 countries globally such as in Malaysia (Othman et al., 2019), China (Xiang et al., 2017), Pakistan (Yousaf et al., 2018) and Sri Lanka (Sun et al., 2017).

There are an estimated 120 million travelers to the subtropical and tropical regions with around two billion people living in developing countries (Banu et al., 2014), of which $40 \%$ are at risk of contracting the dengue virus annually, while the mortality rate is $2.5 \%$ with more cases of classical dengue with severe symptoms (Rasgon, 2011). There were an estimated 390 million cases of dengue infections in 128 countries, with approximately half a million with dengue fever needing hospitalization (WHO, 2020). In Malaysia, a total of 130,101 cases and 182 deaths were reported in 2019, compared to 80,615 cases and 147 deaths in 2018. Most of the cases were reported in the state of Selangor, with 72,543 cases which comprised $55.76 \%$ of the total cases reported in Malaysia (KKM, 2020). The escalation in the number of cases was attributed to poor environmental cleanliness, changes in serotypes and high population density in urban areas.

\section{Control of Mosquitos}

Currently, there are no curative treatments or vaccines available. Therefore, control of the dengue vector is crucial to reduce the transmission of dengue fever. A combination of multidisciplinary approach involving local authorities, mobilization of the community and integration of vector control must be done together to ensure the success of the strategy. However, there are many challenges in the response against dengue outbreaks that include unmanaged and rapid urbanization, poor sanitation systems and bad disposal management in the communities (Chang et al., 2011). 
One of the most effective vector control methods is to control the level of vector populations (Ahmad-Azri et al., 2019; Mazrura et al., 2012). However, most of the vector control strategies nowadays are solely chemical-based, thus without careful monitoring, it will increase the insecticide resistance phenomenon (Besar et al., 2019). This situation has led the WHO and other agencies to demand for more sustainable and reliable strategies (Bourtzis et al., 2016). Thus, it is important to find novel surveillance and prevention strategies for dengue management (Huong et al., 2004). The occurrence of insecticide resistance may vary by geographical distribution due to high usage of pesticides by households and in agriculture. The development of resistance may also become faster and more severe than expected, thus it is essential to control Aedes mosquito populations by eliminating breeding sites through self-initiatives for source reduction in homes and the community (Mazrura et al., 2010).

There are several ways to control a vector population, which are through source reduction, biological control, genetic manipulation, and chemical control (Buhler et al., 2019; Evans et al., 2019; Arham et al., 2018; Awang et al., 2012; Sulaiman et al., 2007). However, the best vector control strategy is to combine source reduction methods, law enforcement and controlling the use of insecticides, which are crucial for the success of any vector control program (Boubidi et al., 2016; Schorkopf et al., 2016). The responsible agencies should prepare several strategies on mosquito management such as performing location assessment, insecticide treatment, educating the public, establishing the policies and regulations, conducting mosquito surveillance and utilizing new technologies (Zaini et al., 2019; Gerding et al., 2016).

The WHO has announced the concept of Integrated Vector Management (IVM) to optimize the use of resources in the management of vector programs that is a rational decision-making for the best management of vector control resources (Sukumaran et al., 2019). The IVM aims to more effectively prevent the transmission of vector-borne diseases such as dengue, chikungunya, malaria and Zika virus, while being more ecologically sound and sustainable (Niang et al., 2018). This strategy implies the collaboration between the public sectors, health sectors and the empowerment of communities by making insecticide application as the last resort. There are five key elements of IVM guidelines: (i) advocacy, social mobilisation and legislation which is enabling the embedding of IVM in policydesign across relevant organisations, (ii) collaboration within the health sector and other agencies, (iii) integrated approach by ensuring the rational use of available tools and resources, (iv) evidence-based decision-making based on local ecology, epidemiology and resources and, (v) capacity-building at national and local level (WHO, 2012). However, without a proper direction, the efficacy of the IVM would not be able to be fully utilized. 


\section{Insect Growth Regulators as an Alternative?}

Insect Growth Regulators (IGR) are the third generation of insecticides that differ from earlier insecticides on their mechanism through influencing insect development, disrupting the activities of the insect endocrine system and metamorphosis (Palli, 2016). In comparison, the first generation of insecticides is characterized by chemicals known throughout human history that include oils and arsenic. The second generation of insecticides includes carbamates, organophosphates, and organochlorides that were synthesized after the discovery of dichlorodiphenyltrichloroethane DDT.

Insect Growth Regulators (IGR) have a selective mechanism in their mode of action that specifically inhibit the development of insects into adults. The mechanisms of IGR delay the transformation and inhibit the cuticle formation in an insect's immature stage (Darabi et al., 2011). IGRs will be applied during the early life stage of the insects and kill the insect before they become adults, and thus unable to reproduce. IGR is a form of "birth control" and can be described as control of insects through the release of hormones/IGR into the populations. It is not necessary for the IGR to have high toxicity against the target sites but enough that it may lead to a change and abnormalities against insect survival. Two compounds are important in regulating the development of insects, namely: (i) ecdysone (also known as molting hormone, $\mathrm{MH}$ ), and (ii) juvenile hormone ( $\mathrm{JH}$ ) which directly interfere with insect metamorphosis, embryogenesis, or reproduction.

Pyriproxyfen is a powerful JH agonist which affects the physiology of metamorphosis, embryogenesis, and reproductivity in insects with a unique mode of action. In general, pyriproxyfen is used in larvicidal activities to control mosquitoes, an example being the Sumilarv ${ }^{\mathrm{TM}}$ brand of IGR. Pyriproxyfen is useful in inhibiting the emergence of adult Aedes spp. and is used in the range of only 0.000048 ppm (Seccacini et al., 2008) to 0.33 ppm (Suman et al., 2017) and could inhibit the emergence of Ae. albopictus with a $\mathrm{LC}_{50}$ and $\mathrm{LC}_{90}$ of 0.0012 ppm and 0.021 ppm respectively (Lau et al., 2015), while the $\mathrm{LC}_{50}$ and $\mathrm{LC}_{90}$ for Ae. aegypti were $0.012 \mathrm{ppb}$ and $0.61 \mathrm{ppb}$, respectively (Sihuincha et al., 2005). These studies proved that pyriproxyfen is one of the most effective larvicides against Aedes species in laboratory settings.

In addition to the larvicidal impact, pyriproxyfen has been reported to reduce the longevity, fertility, and fecundity in exposed mosquitoes. This is a novel strategy as the mosquitoes exposed to the pyriproxyfen are laying unviable eggs. Earlier studies on $A e$. aegypti using sublethal pyriproxyfen doses demonstrated effects on mosquito fecundity and fertility (Harburguer et al., 2014). Due to its environmental persistence, specific activity against insect stages and being non-toxic to mammals, pyriproxyfen is considered as an attractive alternative to conventional insecticides. Furthermore, pyriproxyfen has been evaluated as a safe insecticide for application in drinking water with minimal impacts on non-target aquatic insects and the environment. 


\section{Pull and Push Concept: Autodissemination Potential Against Aedes Spp. Mosquitoes}

Autodissemination is a novel technology to control mosquito populations by exploiting the ability of female mosquitoes to find suitable breeding sites, and on the skip-oviposition, the mosquito will lay their eggs in different containers during a single gonotrophic cycle. The contaminated mosquito is carrying a small particle of insecticide and will transfer it to other mosquitoes via mating, and oviposition in the hidden and cryptic breeding sites that humans may not be able to assess during inspections (Mains et al., 2015). The mechanism of autodissemination approaches is presented in Figure 1. Autodissemination can be considered as pull and push technologies with the attraction and dispersal concept which are beneficial and cost-effective to the vector control program (Unlu et al., 2017). For the autodissemination technique to be successful, specific prerequisites have to be met which are: 1) The ability of the autodissemination station to attract mosquitoes, 2) the autodissemination station is able to transfer the chemical to the mosquitoes and 3 ) the insecticide distribution from the exposed mosquitoes to the breeding sites (Caputo et al., 2012; Gaugler et al., 2012). In addition, another requirement is that the chemical used can work at a low concentration and persists in the environment for a long time (Mains et al., 2015).

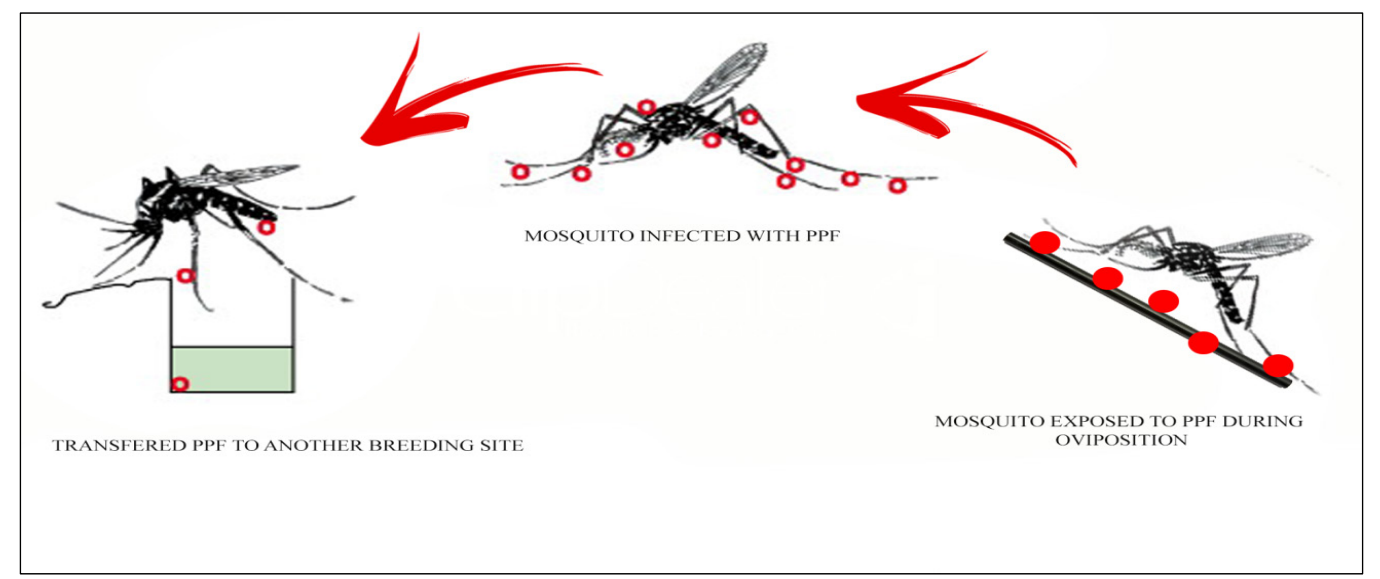

Figure 1. The mechanism of autodissemination of pyriproxyfen by female mosquitoes from exposure containers to other breeding sites.

\section{History of Autodissemination Methods}

The concept of autodissemination devices has been tested on other weeds and pests (Pell et al., 1993; Vega et al., 2000). One example is an automatic device using a fungus as biocontrol agents (BCAs) working as a lure. Once the insect is attracted and enters the 
device, it becomes contaminated and transfers the BCA into populations after leaving the device. The use of BCA dissemination by honey bees was significantly more efficient than conventional sprayers to spread the inoculums against a pest-infested flower (Gross et al., 1994). To enhance the impact of BCAs, the "push-pull" strategy was devised by stimulating the insects out from the population ("push") with feeding the deterrents and extracted ("pull") into the trap. The deterrent lures must be more favorable and attractive than the crop to encourage the insect to enter the traps. In several studies, autodissemination has shown promising results within the pest population when using an attractant device as the initial source of infection (Moslim et al., 2011; Scholte et al., 2004).

Autodissemination has widely been used against diamondback moth (DBM), Plutella xylostella using Zoophthora radican and rhinoceros beetle, Oryctes rhinoceros using Metarhizium anisopliae. The manipulation of DBM behavior using semiochemicals such as pheromones has been used to attract and developed epizootic populations before the critical level was achieved (Pell et al., 1993). Other studies in Klang and Selangor, Malaysia found that the mortality rate of Oryctes rhinoceros was $75 \%$ to $90 \%$ when infected by Metarhizium anisoliae with the percentage of trapped adults leaving the traps ranging from $85 \%$ to $95 \%$ (Moslim et al., 2011).

\section{Autodissemination of Pyriproxyfen on Mosquitoes}

Although there is still a lack of autodissemination field trials, more studies are being carried out on the effectiveness of pyriproxyfen, with some researchers making favourable general conclusions. Most of these studies found that autodissemination did occur and successfully killed the larvae and reduced Aedes spp. populations. Table 1 summarizes the autodissemination studies conducted under semi-field and field settings. The first trial was done in a laboratory (Itoh et al., 1994), and then the concept was furthered by others (Chism \& Apperson, 2003). These studies operated under the assumption that mosquitoes were better at carrying insecticides to their preferred breeding sites compared to human operators. The key to the success of the technique is to use pyriproxyfen in small particles to contaminate mosquitoes which can affect control to the whole area (Gaugler et al., 2012)

A novel method was developed based on the skip oviposition behavior of mosquitoes where female mosquitoes transfer small particles of insecticides to their cryptic breeding sites, thus interrupting the development of the larvae and subsequently killing and reducing the mosquito population in target areas. In 2009, a significant trial for an autodissemination concept with pyriproxyfen was conducted in Iquitos, Peru. The placement of the autodissemination was 5\% from the available resting areas, which achieved a 42-98\% reduction in adult mosquito emergence with a maximum mortality rate of $98 \%$ (Devine et al., 2009). Commercially prepared pyriproxyfen in an emulsifiable concentrate (EC) form was shown to be transferred as far as $200 \mathrm{~m}$ from the treated areas. 
Ahmad Mohiddin Mohd Ngesom, David Greenhalgh, Asmalia Md Lasim, Mazrura Sahani, Rozita Hod and Hidayatulfathi Othman

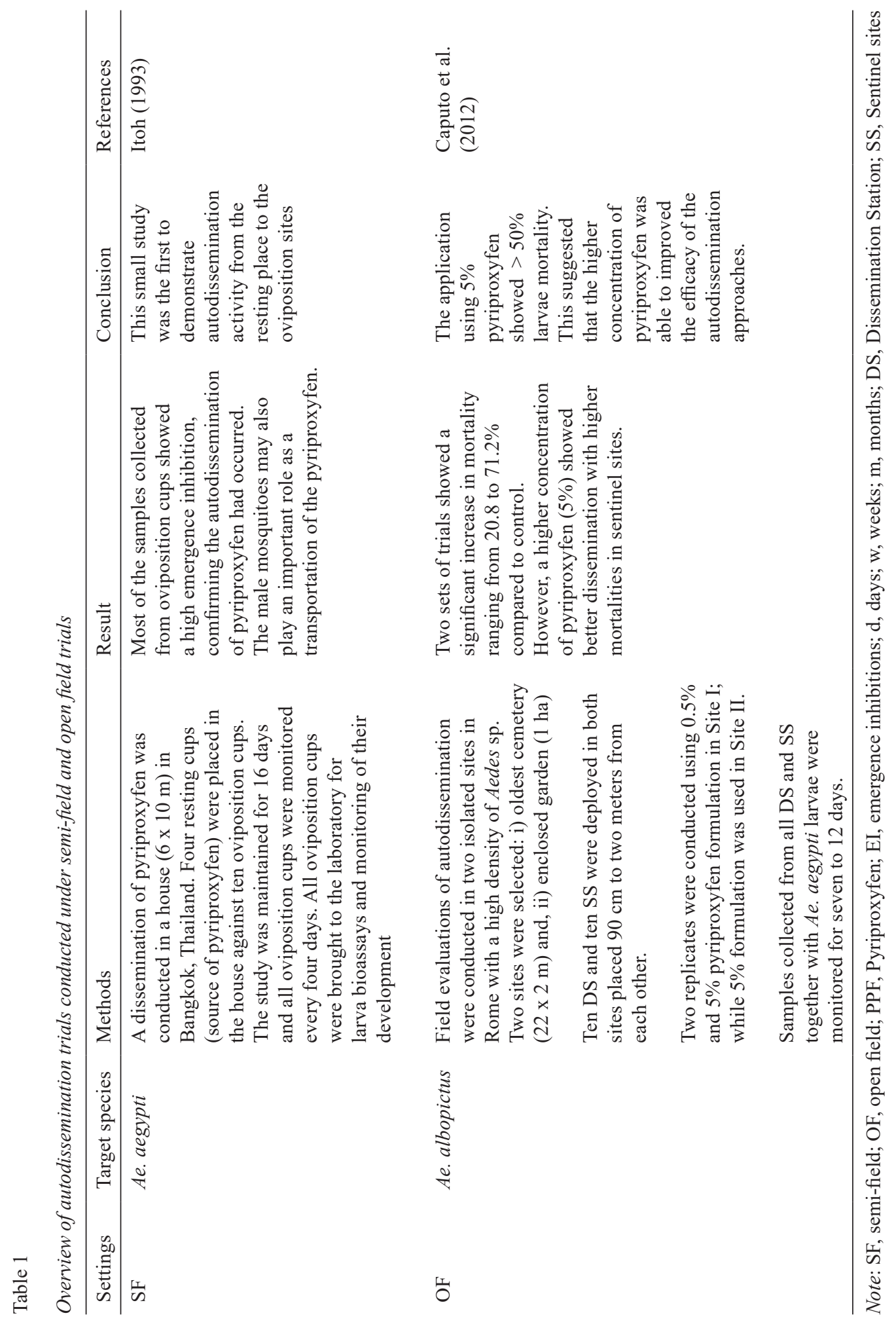


Review of Autodissemination in Vector Control Strategy

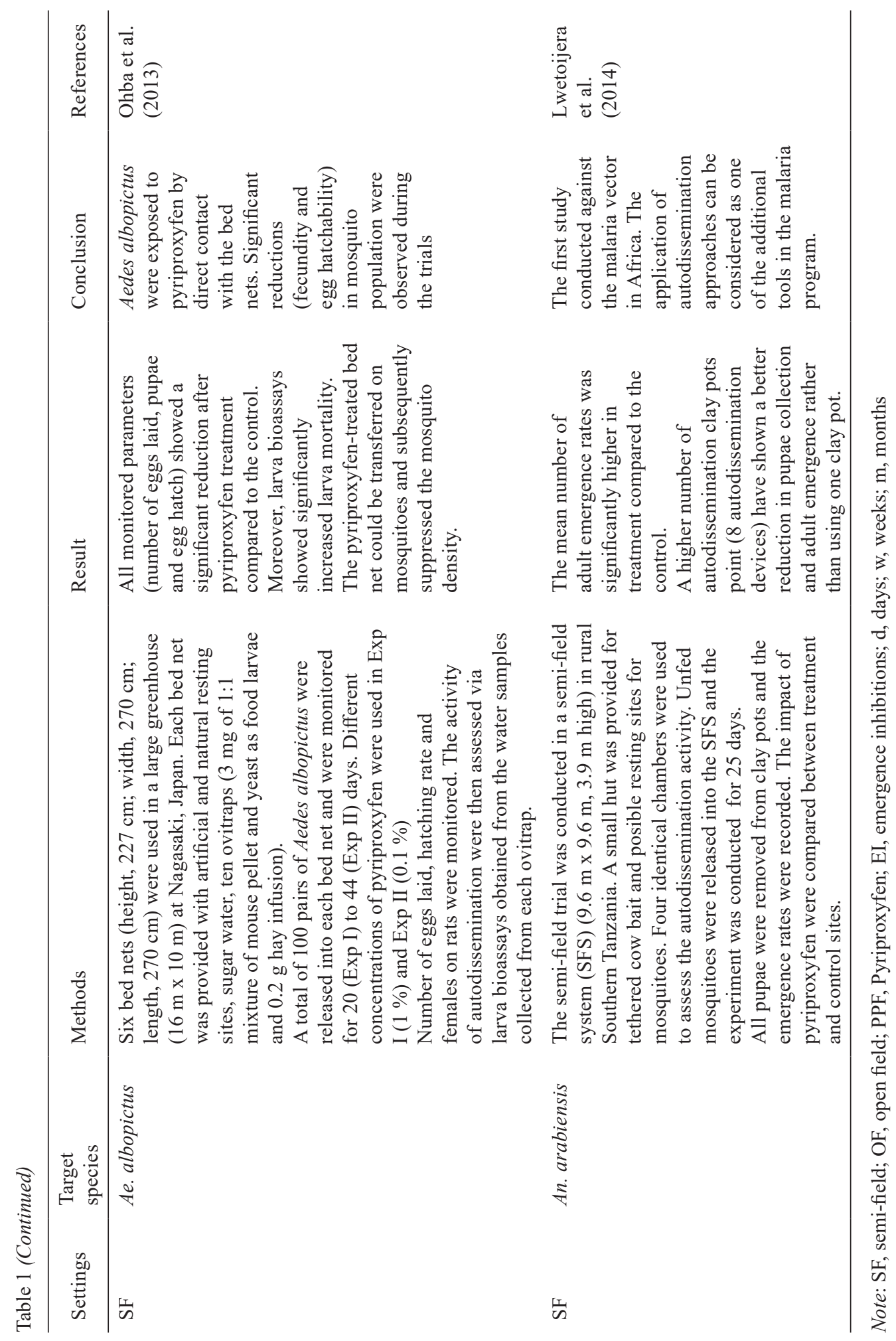


Ahmad Mohiddin Mohd Ngesom, David Greenhalgh, Asmalia Md Lasim, Mazrura Sahani, Rozita Hod and Hidayatulfathi Othman

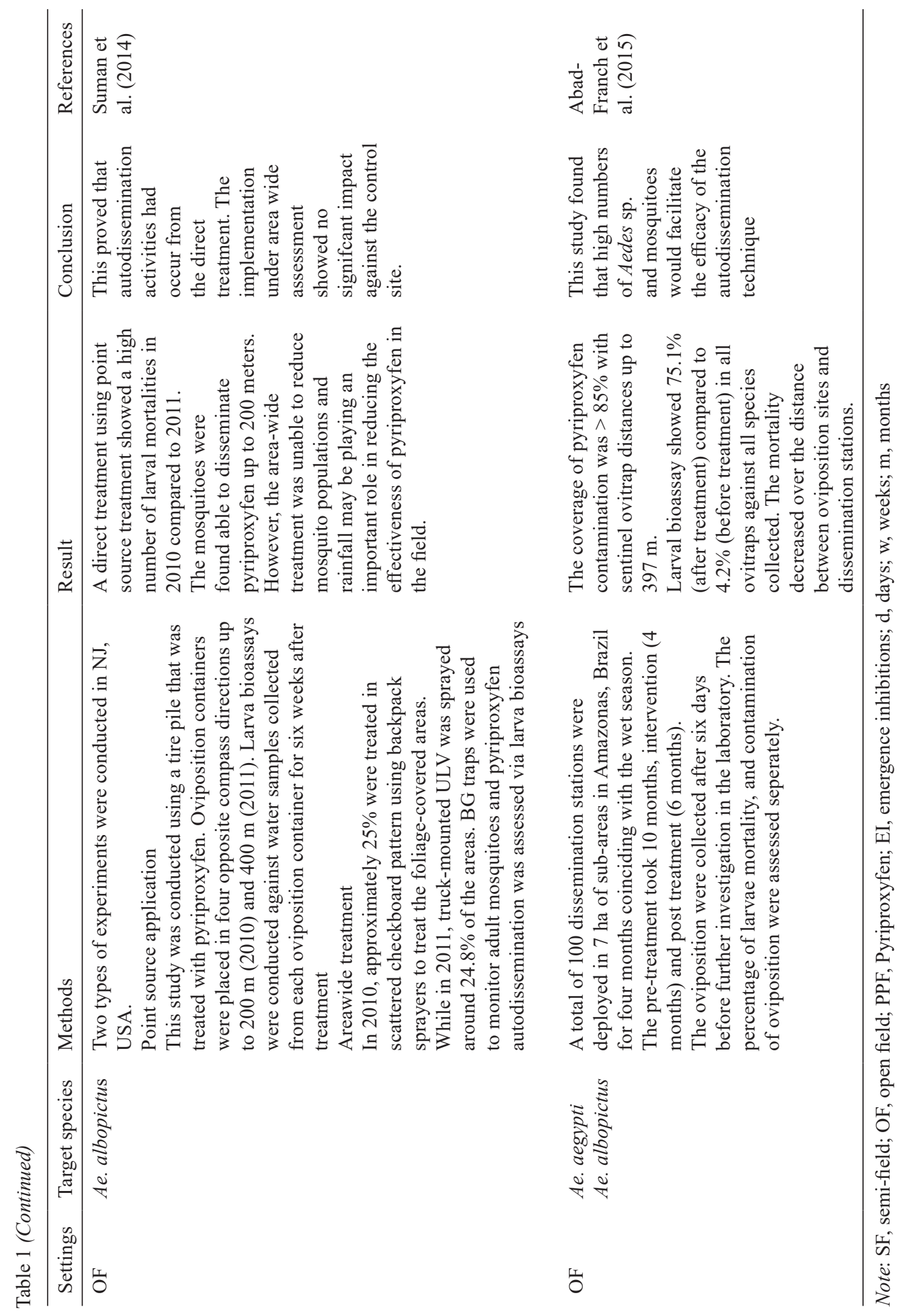


Review of Autodissemination in Vector Control Strategy

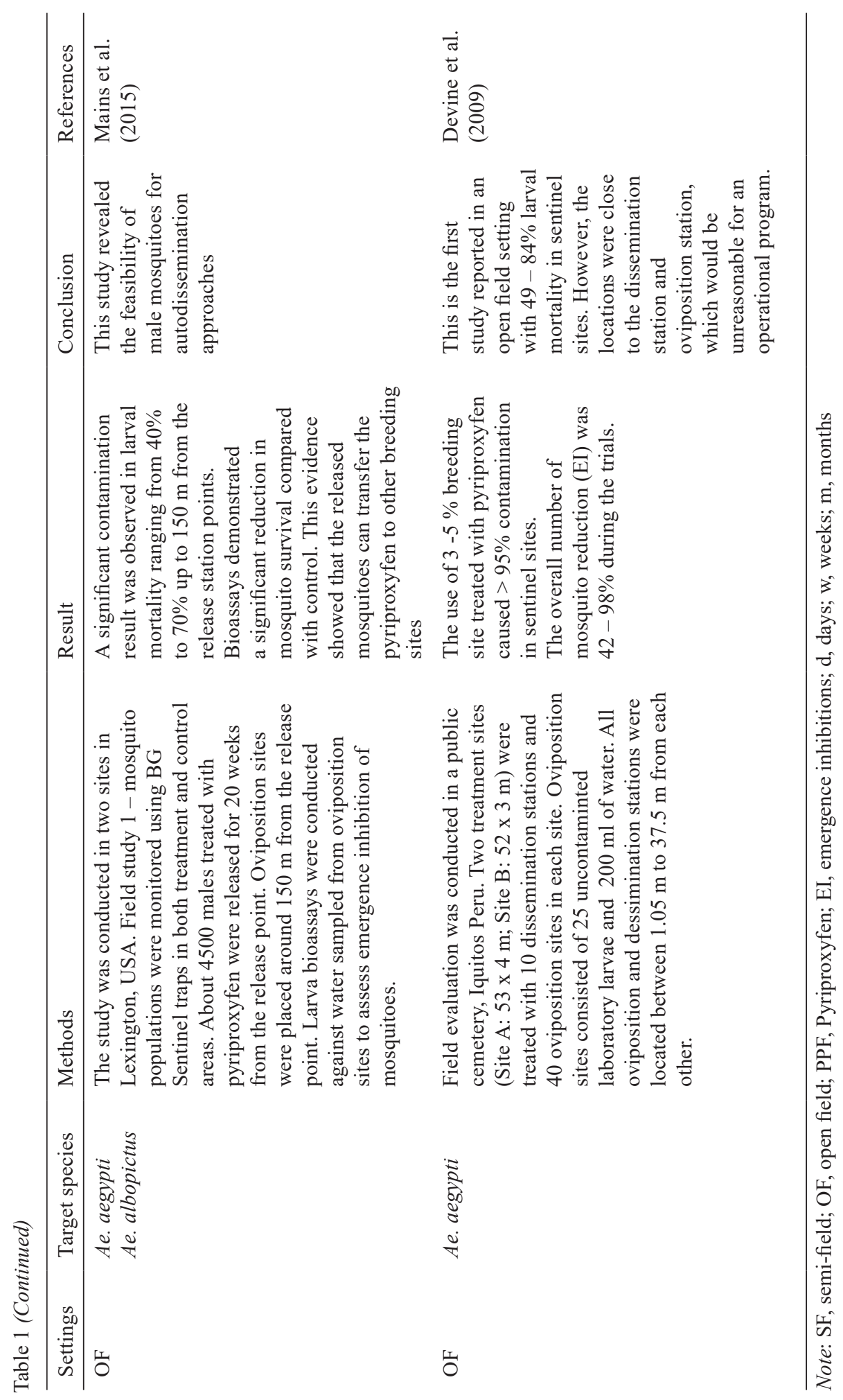


Ahmad Mohiddin Mohd Ngesom, David Greenhalgh, Asmalia Md Lasim, Mazrura Sahani, Rozita Hod and Hidayatulfathi Othman

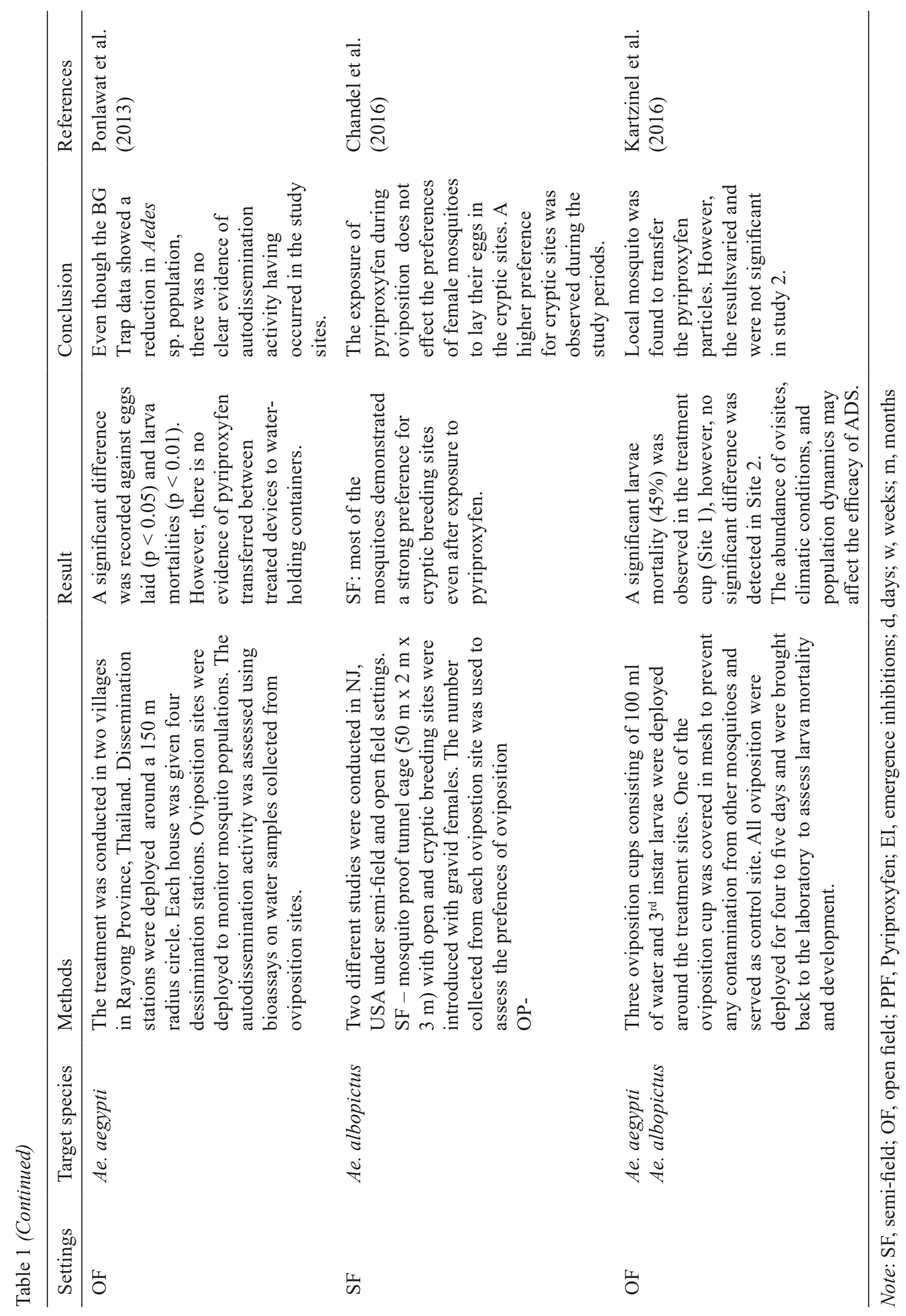


Review of Autodissemination in Vector Control Strategy

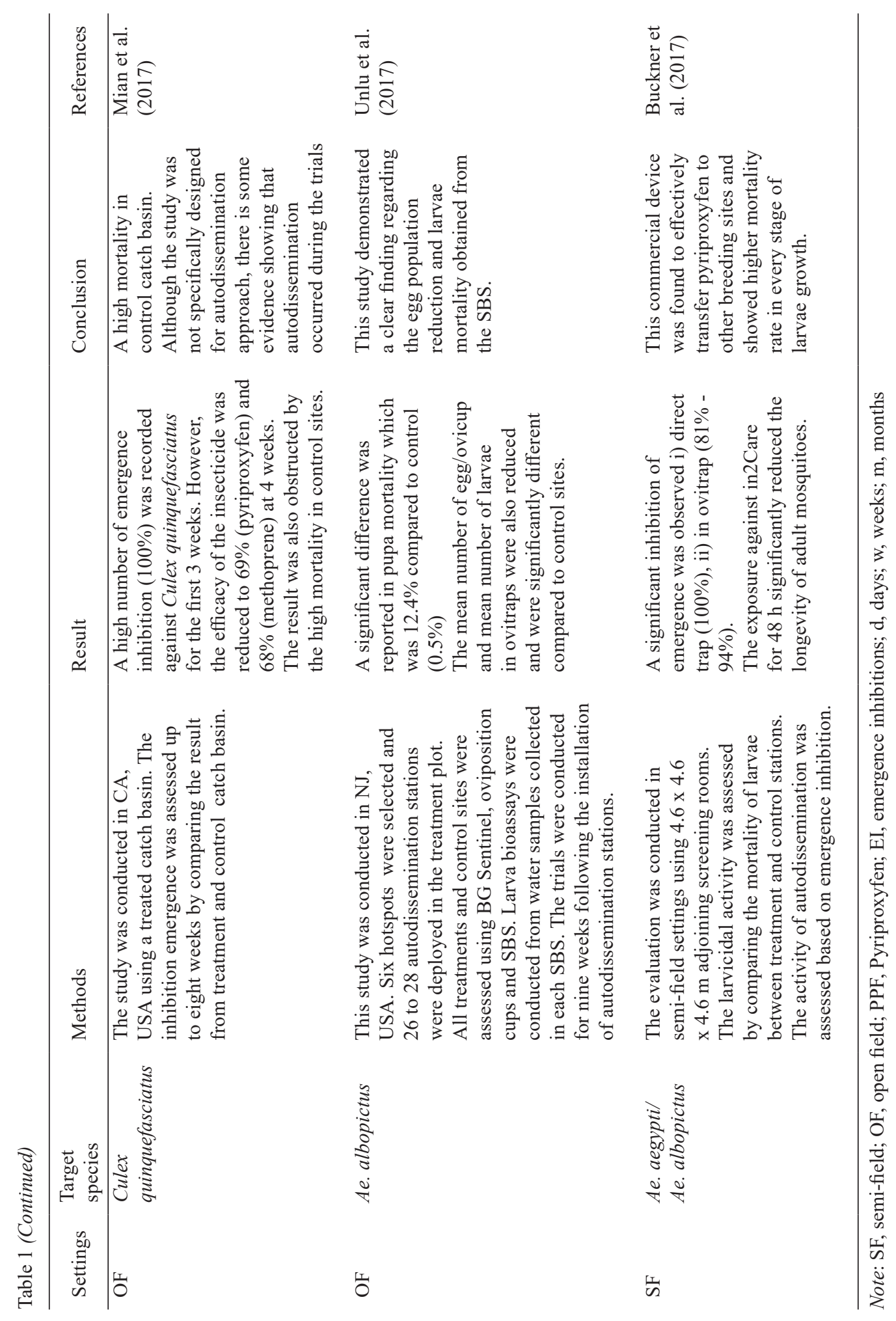


Ahmad Mohiddin Mohd Ngesom, David Greenhalgh, Asmalia Md Lasim, Mazrura Sahani, Rozita Hod and Hidayatulfathi Othman

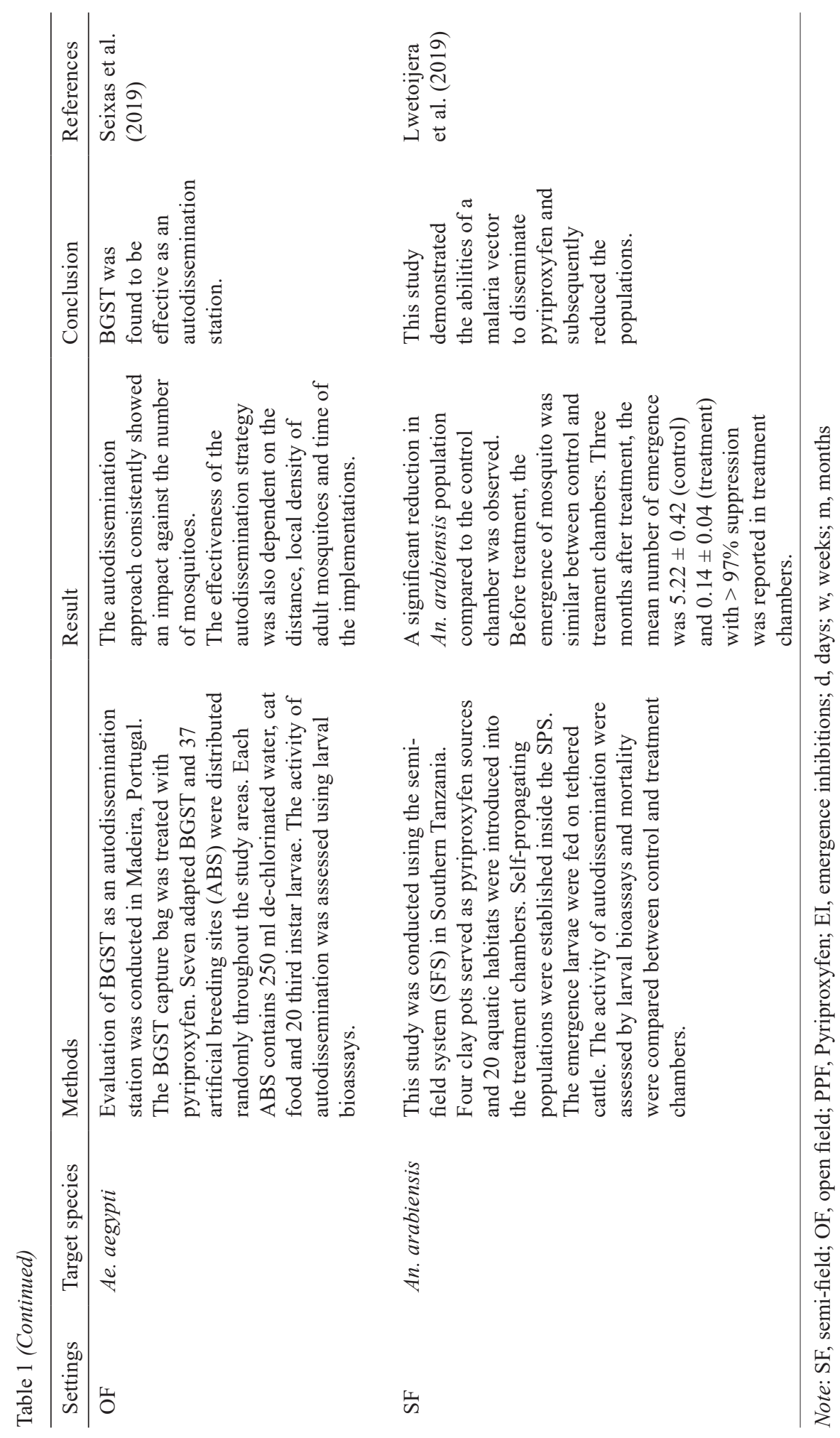


Review of Autodissemination in Vector Control Strategy

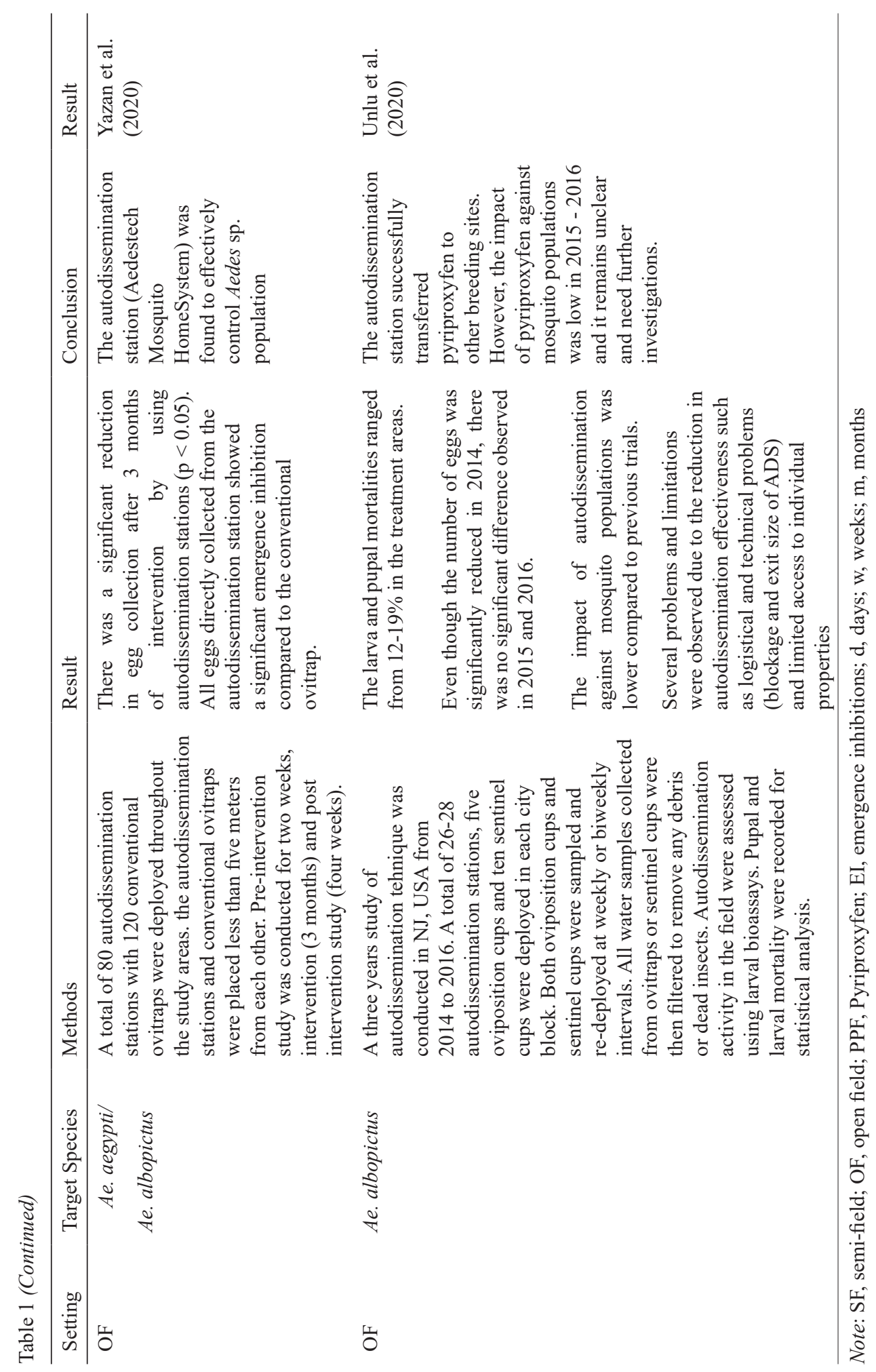


More recently, the effectiveness of autodissemination methods using pyriproxyfen has been studied in Trenton, New Jersey, which was reported to have a high Ae. albopictus population (Unlu et al., 2017). The study showed a reduction in the number of dengue cases, fewer numbers of eggs and residual effects of pyriproxyfen within the treatment areas. Autodissemination has also been studied under different conditions in small-scale field trials against Ae. albopictus and Ae. aegypti (Buckner et al., 2017; Caputo et al., 2012). Moreover, in 2014, the first study against Anopheles arabiensis was conducted in Tanzania, Africa, which observed a $82 \%$ inhibition of adult mosquitoes by using pyriproxyfen autodissemination and similar results were observed against Culex quinquefasciatus and Anopheles gambiae (Mbare et al., 2014). This strategy has shown promising results and can be considered as an alternative vector control against malaria in the future (Lwetoijera et al., 2014). However, a large-scale application of the autodissemination approach needs further investigation.

\section{Recent Advances in Autodissemination on Mosquitoes}

A recent advance in autodissemination is the boosted sterile insect technique (SIT) which is a combination of two methods: releasing sterile mosquitoes and contaminating them with pyriproxyfen. Despite the failure of mating, the percentage of pyriproxyfen contamination between the populations is high. During the mating, male mosquitoes will contaminate females and at the same time can contaminate the breeding sites too. Currently, ongoing research has been conducted to explore the effects of pyriproxyfen against mosquito competitiveness, the amount of pyriproxyfen needed from males to females and then, from females to breeding sites and the design of the smart machines to release the mosquitoes in a large scale (Bouyer \& Lefrancois, 2014).

One study enhanced the persistence of the insecticide and attraction using a dual treatment system involving an EC formulation and granule formulation for the autodissemination stations and showed that the mosquito can carry the insecticide up to $200 \mathrm{~m}$ along the residential areas in the study as detected by residue analysis (Suman et al., 2017). Other studies using a combination of Beauveria bassina (entomopathogenic fungus) and pyriproxyfen also gave 100\% larval mortality in the laboratory; however, the study did not include any field trials (Buckner et al., 2017; Snetselaar et al., 2014). Another approach used a combination of oil and pyriproxyfen to enhance the attachment of the particle on female mosquitoes and increase the transfer of pyriproxyfen to the oviposition sites (Wang et al., 2014).

\section{An Innovation of Autodissemination Device}

An autodissemination station is a new device that has shown promising results in different settings. This device significantly reduced Aedes mosquito populations and subsequently inhibited the transmission of dengue cases. In general, most autodissemination stations 
use a similar concept of attracting mosquitoes to lay their eggs into the traps. Female mosquitoes were then contaminated with pyriproxyfen and transferred the particles to other breeding containers. Some autodissemination stations were developed with their own unique features while still maintaining the basic concept of autodissemination. It is important to determine the effectiveness of prototype autodissemination stations based on their ability to serve as a lethal ovitrap, high mosquito attraction, low cost, biodegradability, and ease of maintenance (Gaugler et al., 2012). These stations are described below and may become widely available with a significant impact on dengue control programs. Thus, a comparative study of autodissemination devices is warranted.

\section{Auto-Dissemination Augmented by Males (ADAM)}

Auto-Dissemination Augmented by Males (ADAM) was developed by using a combination of autodissemination and autocidal concepts, and by enhancing the abilities of male Aedes mosquitoes (Mains et al., 2015). This technique uses mosquitoes as a transporter to transfer pyriproxyfen via mating attempts, and subsequently, it will transfer the pyriproxyfen to cryptic breeding sites during the oviposition. Corbel et al., (2017) found a significant crosscontamination between males and females who were suitable to release the ADAM in areas of low density Aedes populations. Although the density of adult mosquitoes declined after four weeks of treatment, further studies on the mosquito behavior, study area with a different ecological context, as well as the size of the field trials are needed to validate the efficacy of ADAM in the vector control program (Corbel et al., 2017).

\section{In2Care Mosquito Trap}

The In2Care mosquito trap has been approved by the United States Environmental Protection Agency (EPA) for use by professionals against Aedes mosquitoes. It is the first commercial trap that controls both larvae and adult mosquitoes using pyriproxyfen and $B$. bassiana, a fungus with slow-killing abilities on adult mosquitoes, which can be disseminated by affected female mosquitoes. During the oviposition, female mosquitoes will touch their tarsal on a gauze contaminated with pyriproxyfen and B. bassiana. Both agents will stick to the mosquito bodies and be able to disseminate pyriproxyfen to other breeding sites within their flight range (Buckner et al., 2017). The In2Care mosquito traps manipulate the behavior of female mosquitoes by "skip oviposition" and finding cryptic breeding sites. At the same time, the B. bassiana spores will grow hyphae, feed upon the bodies, reproduce and kill the mosquitoes within 18 hours (Ragavendran et al., 2017).

\section{AedesTech Mosquito Home (AHM)}

AedesTech Mosquito Home (AHM) works by using a "pull" and "push" control strategy combined with the lure-kill technology to reduce Aedes populations and interrupting dengue transmission. It has the potential to target larval breeding sites that cannot be reached by 
traditional larvicidal applications (cryptic breeding sites). The "pull" component uses a formulation with an attractant ingredient lure against female mosquitoes to breed inside the AHM while the "push" component refers to the contaminated mosquitoes dispersing after ovipositing their eggs. In this method, female mosquitoes are used as a carrier for the transfer of insecticide to other containers, and thus disseminating the insecticide to the larval habitats (Liang et. at., 2019). The AHM devices have been designed with a sustainable feature in which gravity is used to control the level of water in the casing. During evaporation, water is released in the casing, filling it back to the pre-set level and the evaporation rate will always be kept at the optimum level which is sufficient for the development of Aedes from egg to pupae.

\section{STATUS AND ONGOING STUDIES IN MALAYSIA}

Studies on autodissemination using pyriproxyfen are not well established in Malaysia. Most of the studies conducted were only to evaluate the effectiveness of pyriproxyfen against Aedes spp. mosquitoes. In a study by Nazni et al. (2015), a total of 350 autodissemination devices were deployed in three apartment blocks consisting of 27 storeys with ten-unit houses per floor. Four units of autodissemination were placed at each level at a distance of $5 \mathrm{~m}$ from apartment units. After the exposure periods, there were no viable larvae in the traps, and a significant reduction in number of dengue cases was observed from 53 cases (2013) to 13 cases in 2014. Another study was carried out to explore the additive impact of targeted outdoor residual spraying (TORS) and deployment of autodissemination devices (ADD) in Johor Bharu, Malaysia. Unfortunately, there was no significant effect on the mosquito populations following the combination of TROS and ADD (Hamid et al., 2020).

\section{CONCLUSION}

Vector control programs for arboviruses transmitted by mosquitoes are facing many obstacles. However, with new advances and technologies, it may be viable in the foreseeable future. One of these advances is autodissemination which is a self-delivery technique that manipulates the behavior of mosquitoes to carry insecticides and disseminate it to cryptic breeding sites. Autodissemination has shown promising results in several countries and can be considered as additional tools in a vector control program.

\section{ACKNOWLEDGMENTS}

This work was supported in part by a grant from the Dengue Tech Challenge 2016 (Application Reference DTC 16022), funded through the High-Impact Programme (HIP2) of PlaTCOM Ventures and the Newton-Ungku Omar Fund of the British Council. We thank One Team Networks Sdn Bhd and Prof Dr. Srijit Das for helping with the valuable comment and useful suggestions. 


\section{REFERENCES}

Abad-Franch, F., Zamora-Perea, E., Ferraz, G., Padilla-Torres, S. D., \& Luz, S. L. B. (2015). Mosquitodisseminated pyriproxyfen yields high breeding-site coverage and boosts juvenile mosquito mortality at the neighborhood scale. PLoS Neglected Tropical Diseases, 9(4), 1-17.

Ahmad-Azri, M., Syamsa, R. A., Ahmad-Firdaus, M. S., \& Aishah-Hani, A. (2019). A comparison of different types of ovitraps for outdoor monitoring of Aedes mosquitoes in Kuala Lumpur. Tropical Biomedicine, 36(2): 335-347.

Arham, A. F., Razman, M. R., Amin,L., \& Mahadi, Z. (2018). Dengue review: Issues, challenges and public attitudes. International Journal of Academic Research in Business and Social Sciences, 8(4), 956-972.

Awang, N., Kosnon, N. A., Othman, H., \& Kamaludin, N. F. (2012). The effectiveness of organotin (IV) benzylisopropyldithiocarbamate compounds as insecticides against Aedes aegypti Linn (Diptera: Culicidae) in laboratory. American Journal of Applied Sciences, 9(8), 1214-1218.

Besar, N. A. U. A., Sulaiman, A., Asri, L. N., \& Khairuddin, K. (2019). Resistance status of Aedes aegypti towards different insecticides in selected dengue outbreak area in Petaling District (Diptera: Culicinae). Serangga, 24(2), 41-48.

Banerjee, S., Mohan, S., Pramanik, S., Banerjee, S., Saha, G. K., \& Aditya, G. (2017). Effect of food types on competitive interaction between Aedes aegypti (Linnaeus, 1762) and Ae. albopictus (Skuse, 1894) (Diptera: Culicidae): A proximate level appraisal. Polish Journal of Entomology, 86, 99-118.

Banu, S., Hu, W., Guo, Y., Naish, S., \& Tong, S. (2014). Dynamic spatiotemporal trends of dengue transmission in the Asia-Pacific region, 1955-2004. PLoS One, 9(2), 1-7.

Boubidi, S. C., Roiz, D., Rossignol, M., Chandre, F., \& Benoit, R. (2016). Efficacy of ULV and thermal aerosols of deltamethrin for control of Aedes albopictus in Nice, France. Parasites and Vectors, 9(1), 1-8.

Bourtzis, K., Lees, R. S., Hendrichs, J., \& Vreysen, M. J. B. (2016). More than one rabbit out of the hat: Radiation, transgenic and symbiont-based approaches for sustainable management of mosquito and tsetse fly populations. Acta Tropica, 157, 115-130.

Bouyer, J., \& Lefrancois, T. (2014). Boosting the sterile insect technique to control mosquitoes. Trends in Parasitology, 30(6), 271-273.

Brady, O. J., Johansson, M. A., Guerra, C. A., Bhatt, S., Golding, N., Pigott, D. M., ... \& Styer, L. M. (2013). Modelling adult Aedes aegypti and Aedes albopictus survival at different temperatures in laboratory and field settings. Parasites and Vectors, 6(1), 1-12.

Buckner, E. A., Williams, K. F., Marsicano, A. L., Latham, M. D., \& Lesser, C. R. (2017). Evaluating the vector control potential of the in 2 care $^{\circledR}$ mosquito trap against Aedes aegypti and Aedes albopictus under semifield condition. Journal of American Mosquito Control Association, 33(3), 193-199.

Buhler, C., Winkler, V., Runge-Razinger, S., Boyce, R., \& Horstick, O. (2019). Environmental methods for dengue vector control - A systematic review and meta-analysis. PLoS Neglected Tropical Diseases, $13(7), 1-15$. 
Camara, D. C. P., Codeco, C. T., Juliano, S. A., Lounibos, L. P., Riback, T, I, S., \& Honorio, N. A. (2016). Seasonal differences in density but similar competitive impact of Aedes albopictus (Skuse) on Aedes aegypti (L.) in Rio de Janeiro, Brazil. PloS ONE, 11(6), 1-15.

Caputo, B., Lenco, A., Cianci, D., Pombi, M., Petrarca, V., Baseggio, A., ... \& della Torre, A. (2012). The autodissemination approach: A novel concept to fight Aedes albopictus in urban areas. PLoS Neglected Tropical Disease, 6(8), 1-8.

Caraballo, H., \& King, K. (2014). Emergency department management of mosquito-borne illness: Malaria, dengue and west nile virus. Emergency Medicine Practice, 16(5), 1-23.

Chandel, K., Suman, D. S., Wang, Y., Unlu, I., Wiliges, E., Williams, G. M., \& Gaugler, R. (2016). Targeting a hidden enemy: Pyriproxyfen autodissemination strategy for the control of the container mosquito Aedes albopictus in cryptic habitats. PLoS Neglected Tropical Diseases, 10(12), 1-15.

Chang, M. S., Christophel, E. M., Gopinath, D., \& MdAbdur, R. (2011). Challenges and future perspective for dengue vector control in the Western Pacific Region. Western Pacific Surveillance and Response Journal, 2(2), 9-16.

Chism, B. D., \& Apperson, C. S. (2003). Horizontal transfer to the insect growth regulator pyriproxyfen to larval microcosms by gravid Aedes albopictus and Ochlerotus triseriatus mosquitoes in the laboratory. Medical and Verterinary Entomology, 17, 211-220.

Corbel, V., Fonseca, D. M., Weetman, D., Pinto, J., Achee, N. L., Chandre, F., .. \& David, J. P. (2017). International workshop on insecticide resistance in vectors of arboviruses, December 2016, Rio de Janeiro, Brazil. Parasites and Vectors, 10, 1-16.

Darabi, H., Vatandoost, H., Abaei, M. R., Gharibi, O., \& Pakbaz, F. (2011). Effectiveness of methoprene, an insect growth regulator, against malaria vectors in Fars, Iran: A field study. Pakistan Journal of Biology Sciences, 14, 69-73.

Delatte, H., Desvars, A., Boutard, A., Bord, S., Gimonneau, G., Vourc'h, G., \& Fontenille, D. (2010). Bloodfeeding behaviour of Aedes albopictus a vector of chikungunya on La Reunion. Vector Borne and Zoonotic Diseases, 10(3), 249-258.

Devine, G. J., Perea, E. Z., Killeen, G. F., Stancil, J. D., Clark, S. J., \& Morrison, A. C. (2009). Using adult mosquitoes to transfer insecticides to Aedes aegypti larval habitats. Proceedings of the National Academy of Sciences, 106(28), 11530-11534.

Evans, B. R., Kotsakiozi, P., Costa-da-Silva, A. L., Ioshino, R. S., Garziera, L., Pedrosa, M. C., ... \& Powell, J. R. (2019). Transgenic Aedes aegypti mosquitoes transfer gene into a natural population. Scientific Reports, 9(1), 1-6.

Faraji, A., Egizi, A., Fonseca, D. M., Unlu, I., Crepeau, T., Healy, S. P., \& Gaugler, R. (2014). Comparative host pattern of the tiger asian tiger mosquito, Aedes albopictus, in urban and suburban Northeastern USA and implication for disease transmission. PLoS Neglected Tropical Diseases, 8(8), 1-11.

Gaugler, R., Suman, D., \& Wang, Y. (2012). An autodissemination station for the transfer of an insect growth regulator to mosquito oviposition sites. Medical and Veterinary Entomology, 26, 37-45. 
Gerding, J., Kirshy, M., Moran, J. W., Bialek, R., Lamers, V., \& Sarisky, J. (2016). A performance management initiative for local health department vector control programs. Environmental Health Insight, 10, 113-118.

Gross, H. R., Hamm, J., \& Carpenter, J. E. (1994). Design and application of a hive-maintained device uses honey bee (Hymenoptera: Apidae) to disseminate Heliothis nuclear polyhedrosis virus. Environmental Entomology, 23, 492-501.

Hamid, N. A., Alexander, N., Suer, R., Ahmed, N. W., Mudin, R, N., Omar, T., ... \& Saadatian-Elahi, M. (2020). Targeted outdoor residual devices and their combination against Aedes mosquitoes: Field implementation in a Malaysia urban settings. Bulletin of Entomological Research, 110(4), 1-8.

Harburguer, L., Zerba, E., \& Licastro, S. (2014). Sublethal effect of pyriproxyfen released from a fumigant formulation on fecundity, fertility and ovicidal action in Aedes aegypti (Diptera: Culicidae). Journal of Medical Entomology, 51(2), 436-443.

Hopperstad, K. A., \& Reiskind, M. H. (2016). Recent changes in the local distribution of Aedes aegypti (Diptera: Culicidae) in South Florida, USA. Journal of Medical Entomology, 53(4), 836-842.

Huong, V. D., Ngoc, N. T. B., Hein, D. T., \& Lien, N. T. B. (2004). Susceptibility of Aedes aegypti to insecticide in Viet Nam. Dengue Bulletin, 28, 179-183.

Itoh, T. (1993). Control of DF/ DHF vectors, Aedes mosquito, with insecticides. Tropical Medicine,35(4), 259-267.

Itoh, T., Kawada, H., Abe, A., Eshita, Y., Rongsriyam, Y., \& Igarashi, A. (1994). Utilization of bloodfed females of Aedes aegypti as vehicle for the transfer of the insect growth, pyriproxyfen to larval habitats. Journal of American Mosquito Control Association, 10(3), 344-347.

Kartzinel, M. A., Alto, B. W., Deblasio, M. W., \& Burkertt-Cadena, N. D. (2016). Testing of visual and chemical attractants in correlation with the development and field evaluation of an autodissemination station for the suppression of Aedes aegypti and Aedes albopictus in Florida. Journal of American Mosquito Control Association, 32(3), 194-202.

KKM. (2020). Kenyataan akhbar ketua pengarah kesihatan Malaysia mengenai situasi semasa demam denggi, zika dan chikungunya di Malaysia -ME 23.2020 [Press Statement Minister of Health Malaysia - Current Situation of Dengue, Chikungunya and Zika in Malaysia - EW 23. 2020]. Retrieved July 17, 2020, from https://www.moh.gov.my/index.php/database_stores/store_view_page/21/1622

Lau, K. W., Chen, C. D., Lee, H. L., \& Sofian-Azirun, M. (2015). Evaluation of insect growth regulators, temephos and Bacillus thuringiensis israelensis against Aedes aegypti (L) in plastic containers. Tropical Biomedicine, 32(4), 684-692.

Liang, Y., Ahmad Mohiddin, M. N., Bahauddin, R., Hidayatul, F. O., Nazni, W. A., Lee, H. L., \& Greenhalgh, D. (2019). Modelling the effect of a novel autodissemination trap on the spread of dengue in Shah Alam and Malaysia. Computational and Mathematical Methods in Medicine, 2019(1923479), 1-15.

Lwetoijera, D., Harris, C., Kiware, S., Dongus, S., Devine, G. J., McCall, P. J., \& Majambere. (2014). Effective autodissemination of pyriproxyfen to breeding sites by the exophilic malaria vector Anopheles arabiensis in semi-field setting in Tanzania. Malaria Journal, 13(1), 1-10. 
Lwetoijera, D., Kiware, S., Okumu, F., Devine, G. J., \& Majambere, S. (2019). Autodissemination of pyriproxyfen suppress stable populations of Anopheles arabiensis under semi-controlled settings. Malaria Journal, 18(1), 1-10.

Mains, J. W., Brelsfoard, C. L., \& Dobson, S. L (2015). Male mosquitoes as vehicle for inscticide. PLoS Neglected Tropical Diseases, 9(1), 1-17.

Mazrura, S., Rozita, H., Hidayatulfathi, O., Zainudin, M. A., Naim, M. R., Nadia, A. M. N., ... \& Joy, J. P. (2010). Community vulnerability on dengue and its association with climate variability in Malaysia: A public health approach. Malaysia Journal of Public Health Medicine, 10(2), 25-34.

Mazrura, S., Othman, H., Nor, N. A. M., Hod, R., Ali, Z. M., Rasidi, M. N. M., .. \& Choy, E. A. (2012). Kajian ekologi nyamuk Aedes di Senawang Negeri Sembilan, Malaysia [Ecology Survey on Aedes Mosquito in Senawang, Negeri Sembilan]. Sains Malaysiana, 41(2), 261-269.

Mbare, O., Lindsay, S. W., \& Filinger, U. (2014). Pyriproxyfen for mosquito control: Female sterilization or horizontal to oviposition substrate by Anopheles gambiae sensu stricto and Culex quinquefasciatus. Parasites and Vectors, 7(1), 1-12.

Mian, L. S., Dhillon, M. S., \& Dodson, L. (2017). Field evaluation of pyriproxyfen against mosquitoes in catch basins in Southern California. Journal of American Mosquito Control Association, 33(2), 145-147.

Moslim, R., Kamarudin, N., \& Wahid, M. B. (2011). Trap for autodissemination of Metarhizium anisopliae in the management of rhinoceros beetle, Oryctes rhinoceros. Journal of Oil Palm Research, 23, 1011-1017.

Nazni, W. A., Teoh, G. N., Farah, H., Suhana, O., Sakinah, A., Chandru, A., .. \& Lee, H. L. (2015, March 3-4). Field evaluation of auto-dissemination of dengue in high-rise condominium in Selangir. In $51^{s t}$ Annual Scientific Seminar of the Malaysian Society of Parasitology and Tropical Medicine. Kuala Lumpur, Malaysia.

Niang, E. H. A., Bassene, H., Fenollar, F., \& Mediannikov, O. (2018). Biological control of mosquito-borne diseases: the potential of Wolbachia-based interventions in an IVM framework. Journal of Tropical Medicine, 2018, 1-15.

Ohba, S. Y., Ohashi, K., Pujiyati, E., Higa, Y., Kawada, H., Nobuaki, M., \& Masairo, T. (2013). The effect of pyriproxyfen as a "population growth regulator" against Aedes albopictus under semi-field condition. PLoS One, 8(7), 1-10.

Othman, H., Zaini, Z. I., Karim, N., Rashid, N. A. A., Abas, M. B. H., Sahani, M., ... \& Nor, N. A. M. (2019). Applying health belief model for the assessment of community knowledge, attitude and prevention practices following a dengue epidemic in a township in Selangor, Malaysia. International Journal of Community Medicine and Public Health, 6(3): 958-970.

Palli, S. R. (2016). Hormonal regulation of development and reproduction. In H. Czosnek \& M. Ghanim (Eds.), Management of insect pest to agriculture (pp. 99-114). Cham, Switzerland: Springer.

Pell, J. K., Macaulay, E. D. M., \& Wilding, N. (1993). A pheromone trap for dispersal of the pathogen Zoophthora radicans Brefeld (Zygomycetes: Entomopthorales) amongst populations of the diamondback moth, Plutella xylostella L. (Lepidoptera: Yponomeutidae). Biocontrol Science and Technology, 3, 315-320. 
Ponlawat, A., Fansiri, T., Kurusarttra, S., Pongsiri, S., McCardle, P. W., Evan, B. P., \& Ricardson, J. H. (2013). Development and evaluation of a pyriproxyfen-treated device to control the dengue vector, Aedes aegypti (L.) (Diptera: Culicidae). The Southeast Asian Journal of Tropical Medicine and Public Health, 44(2), 167-178.

Ragavendran, C., Dubey, N. K., \& Natarajan, D. (2017). Beauveria bassiana (Clavicipitaceae): A potent fungal agent for controlling mosquito vectors of Anopheles stephensi, Culex quinquefasciatus and Aedes aegypti (Diptera: Culicidae). RSC Advances, 7, 3838-3851.

Rasgon, J. L. (2011). Mosquitoes attacked from within. Nature, 476, 407-408.

Scholte, E. J., Knols, B. G. J., \& Takken, W. (2004). Autodissemination of the entomopathogenic fungus Metarhizium anisopliae amongst adult of the malaria vector Anopheles gambiae s.s. Malaria Journal, $3(1), 1-6$.

Schorkopf, D. L. P., Spanoudis, C. G., Mboera, L. E. G., Mafra-Neto, A., Ignell, R., \& Dekker, T. (2016). Combining attractants and larvicides in biodegradebale matrices for sustainable mosquito vector control. PLoS Neglected Tropical Diseases, 10(10), 1-22.

Seccacini, E., Lucia, A., Harburguer, L., Zerba, E., Licastro, S., \& Masuh, H. (2008). Effectiveness of pyriproxyfen and diflubenzuron formulations as larvicides against Aedes aegypti. Journal of the American Mosquito Control Association, 24(3), 398-403.

Seixas, G., Paul, R. E., Pires, B., Alves, G., de Jesus, A., Silva, A. C., ... \& Sousa, C. A. (2019). An evaluation of efficacy of the auto-dissemination technique as a tool for Aedes aegypti control in Madeira, Portugal. Parasites and Vectors, 12(1), 1-13.

Sihuincha, M., Zamora-Perea, E., Orellana-Rios, W., Stancil, J. D., Sifuentes, V. L., Vidal-Ore, C., \& Devine, G. J. (2005). Potential use of pyriproxyfen for control of Aedes aegypti (Diptera: Culicidae) in Iquitos, Peru. Journal of Medical Entomology, 42(4), 620-630.

Snetselaar, J., Andriessen, R., Suer, R. A., Osinga, A. J., Knol, B. G. J., \& Farenhost, M. (2014). Development and evaluation of a novel contamination device that targets multiple life-stages of Aedes aegypti. Parasite and Vectors, 7(1), 1-10.

Sukumaran, B., Kandasamy, K., Ramanathan, S., Tom, A., \& Rajagopal, S. S. (2019). Review on current status of dengue and its prevention in India. International Journal of Research in Pharmaceutical Sciences, $10(4), 2748-2754$.

Sulaiman, S., Fadhlina, K., \& Othman, H. (2007). Evaluation of pyrethtin formulations on dengue/dengue haemorrhagic fever vectors in the laboratory and sublethal effects. Iranian Journal Athropod-Borne Diseases, 1(2), 1-6.

Suman, D. S., Farajollahi, A., Healy, S., Williams, G. M., Wang, Y., Schoeler, G., \& Gaugler, R. (2014). Pointsource and area wide field studies of pyriproxyfen autodissemination against urban container-inhabiting mosquitoes. Acta Tropica, 135, 96-103.

Suman, D. S., Wang, Y., Faraji, A., Williams, G. M., Wiliges, E., \& Gaugler, R. (2017). Seasonal field efficacy of pyriproxyfen autodissemination stations against container-inhabiting mosquito Aedes albopictus under different habitat conditions. Pest Management Science, 74(4), 885-895. 
Sun, W., Xue, L., \& Xie, X. (2017). Spatial-temporal distribution of dengue and climate characteristics for two clusters in Sri Lanka from 2012 to 2016. Scientific Reports, 7(1), 1-12.

Unlu, I., Rochlin, I., Suman, D. S., Wang, Y., Chandel, K., \& Gaugler, R. (2020). Large-scale operational pyriproxyfen autodissemination deployment to suppress the immatureasian tiger mosquito (Diptera: Culicidae) populations. Journal of Medical Entomology, 57(4), 1120-1130.

Unlu, I., Suman, D. S., Klinger, K., Faraji, A., \& Gaugler, R. (2017). Effectiveness of autodissemination stations containing pyriproxyfen in reducing immature Aedes albopictus populations. Parasites and Vectors, 10(1), 1-10.

Vega, F. E., Dowd, P. F., Lacey, L. A., Pell, K., Jackson, D. M., \& Klein, M. (2000). Trapping for autodissemination of entomopathogens. In L. A. Lacey \& H. Kaya (Eds.), Field manual techniques in insect pathology (pp. 153-176). Dordrecht, The Netherlands: Kluwer Academic Publisher.

Wang, Y., Suman, D. S., Bertrand, J., Dong, L., \& Gaugler, R. (2014). Dual-treatment autodissemination station with enhances transfer of an insect growth regulator to mosquito oviposition sites. Pest Management Sciences, 70(8), 1299-304.

WHO. (2012). Handbook for integrated vector management. Retreived June 18, 2020, from https://apps.who. int/iris/bitstream/handle/10665/44768/9789241502801_eng.pdf;jsessionid=B4DDA992C5E2E6850169 0DE62289B785?sequence $=1$

WHO. (2016). Fact sheet on vector-borne disease. Retreived March 30, 2020, from https://www.who.int/en/ news-room/fact-sheets/detail/vector-borne-diseases

WHO. (2020). Global strategy for dengue prevention and control 2012-2020. Retreived March 30, 2020, from https://apps.who.int/iris/bitstream/handle/10665/75303/9789241504034_eng.pdf?sequence=1

Wong, P. S., Li, M. Z. I., Chong, C. S., Ng, L. C. \& Tan, C. H. (2013). Aedes (Stegomyia) albopictus (Skuse): A potential vector of zika virus in Singapore. PLoS Neglected Tropical Diseases, 7(8), 1-5.

Xiang, J., Hansen, A., Liu, Q., Liu, X., Tong, M. X., Sun, Y., ... \& Bi, P. (2017). Association between dengue fever incidence and meteorological factors in Guangzhou, China, 2005-2014. Environmental Research, $153,17-26$.

Yazan, L. S., Paskaran, K., Gopalsamy, B., \& Majid, R. A. (2020). Aedestech mosquito home system prevents the hatch of Aedes mosquito eggs and reduces its population. Pertanika Journal Science and Technology, 28(1), 263-278.

Yousaf, M. Z., Siddique, A., Ashfaq, U. A., \& Ali, M. (2018). Scenario of dengue infection \& its control in Pakistan: an update and way forward. Asian Pacific Journal of Tropical Medicine, 11(1), 15-23.

Zaini, Z. I. I., Othman, H., Karim, N., Rashid, N. A. A., Abas, M. B. H., Sahani, M., ... \& Nordin, S. A. (2019). Knowledge and practices regarding Aedes control amongst residents of dengue hotspot area in Selangor: A cross-sectional study. Sains Malaysiana, 48(4), 841-849. 